\title{
Centralização e Descentralização
}

\author{
Carlos Eduardo de Oliveira Valle
} $-\mathrm{I}-$

$\mathrm{D}$

ESCENTRALIZAÇão administrativa está na ordem do dia. Realmente acreditamos que ninguém de bom senso ousaria hoje contraditar que, tanto no Govêrno como nas emprêsas privadas de grande porte, as antigas tendências de alta centralização organizacional e concentração de podêres, já não têm mais possibilidade de conduzir aos desejados padrões de eficiência, dentro do quadro tecnológico atual.

2. Fala-se, por isso, e freqüentemente, em descentralizar e desconcentrar podêres do centro para a periferia das decisões.

3. Se as idéias estão certas, no particular caso das grandes organizações, não menos certas, contudo, são as cautelas especiais a serem adotadas no planejamento, tanto da descentralização. no sentido da estrutura, como na delegação, no sentido do cometimento das atribuições de decidir às autoridades menores.

4. Fundamental em ambos êsses aspectos a observância do preceito, se não rigido, pelo menos digno de ser sempre considerado, de que quanto mais descentralizamos, maior a necessidade de meios de contrôle. Aqui um dos pontos nevrálgicos: dar dimensão maicr à descentralização e delegar o quantum satis, mas "arrochar" os contrôles. É a liberdade controlada de decisão dos canais inferiores, sem que, no entanto, a ação respectiva, ainda que por constatação "a posteriori", não escape ao conhecimento e à conseqü znte possibilidade de correção ou reformulação do processo decisório.

5. U outro importante aspecto - êste condizente com o comportamento individual - é o imprescindivel preparo (especifico) do pessoal, aqui se incluindo a formação e o treinamento adequados ao exercício da função delegada. De tato, é perigoso - e seria até contraproducente - descentralizarmos ou deleqarmos autoridade, sem antes cogitarmos se na organizaçao os i:mpregados, ou, no Govêrno, os funcionários, estão suficientemente preparados para enfrentarem decisões. Isto é tanto mais impor- 
tante, no atual estágio de evolução das ciências administrativas, quando sabemos que so recentemente os autores e administradores passaram a encarar o indivíduo fora daquela passividade, daquele automatismo, como antes, e em largo tempo, se o considerou.

6. Todos, ou quase todos, os chamados clássicos da Ciência da Administração - e disso não escapam Fayol, Taylor, Urvick e Gullick, partiram sempre, ao elaborar seus principios de Administração, de gerência cientifica ou de teoria de departamentalização, do homem como figura estática, passiva, que, supostamente sempre, sem variações, teriam que cumprir, com o mesmo comportamento (no sentido psicológico) suas tarefas especificas.

7. Sabemos que há uma revolução em marcha neste aspecto, o do comportamento dos empregados, como fator variante indispensável de ser levado em conta, qualquer que seja a teoria ou o processo de organização (v. Teoria das Organizaçes, de J.G. Marsh e H.A. Simon).

8. Essas novas idéias - frise -se - vêm trazer maior alento ao processo da delegação e isto porque, partindo da noção dos empregados como instrumentos ativos, capazes de receber ordens, (processos clássicos de organização) elas hoje pressupõem que os membros da organização são tomadores de decisão e resolvedorcs de problemas (Of. cit., pág. 9).

9. E é isto, justamente, o que buscam e, de certn modo, exigem a descentralização e a delegação.

\section{II}

10. Estas as idéias introdutórias.

11. Vejamos agora alguns aspectos mais chegados à orga. nização, onde se procura demonstrar "o que", "como" e "quando"
se deve centralizar ou descentralizar.

\section{III}

12. Há várias maneiras de se organizar a administração, conforme o âmbito, a importância e a amplitude da emprêsa.

13. Atendendo-se, precìpuamente, àqueles fatôres, e, além dêsses, a uma série de circunstâncias outras e peculiaridades, pode a organização ser centralizada, descentralizada, ou, então, nas grandes emprêsas - obedecer ao que se chama "sistema", ou seja, centralizarem-se determinadas atividades - especialmente, as de as de teormativo - e descentralizarem-se, no todo ou em parte, 
14. Se bem que, na prática, nem sempre o órgão central exerça, exclusivamente, atividades normativas, de um modo geral, devem elas ser as predominantes. Competem, dêsse modo, pri:z cipalmente, ao organismo central, além de tôda a orientação geral, a coordenação e o contrüle.

15. Só assim é permitida uma visão global, ou panorâmica, dos problemas decorrentes da execução das atividades da administração, dentro da emprêsa, que, entretanto, para se tornar concreta e atualizada, sempre, precisa ter caráter permanente. Isto se obiém através de rotinas que permitam o pleno conhecimento, de preferência prèviamente, ou, pelo menos, a posteriori, de tôdas as alterações, básicas, ainda que autorizadas por delegação de competência.

16. De fato, é indispensável que a coordenação e o contiôle sejam exercidos pelo órgão central, sôbre os atos que importem em alterações quantitativas e qualitativas. Tal atribuição - embora outras possam suscitar dúvidas - é, para todos os entendidos no assunto, indiscutivelmente, do órgão central.

17. Esta opinião, que é, afinal, a de todos, está definida pelo Professor Henry Reining Jr. - Deão da Universidade de Southern - Califórnia - USA, o conhecido especialista no assunto -dando como uma das atribuições básicas do órgão central, no caso, o de pessoal, a de:

"Assistir o chefe do Executivo na manutenção do necessário contrôle central sôbre a administração de pessoal, a fim de assegurar a aplicação de diretrizes construtivas e de coordená-las com a politica geral de administração" (v. Cadernos de Adm. Publ. - FGV n" 12 - "As Funções de Administração de Pessoal", H. Reining Jr., pág. 38).

18. Mas, então, pergunta-se: como é possível o exercício do contrôle e da coordenação, por parte do órgão central?

19. É claro que, qualquer que seja o método, no particular, êle terá sempre por ponto de partida o conhecimento, prévio ou não, de tudo o que, na execução, fôr praticado. Êste "tudo", como é óbvio, refere-se ao básico, às alterações fundamentais, cujos contrôle e coordenação forem julgados necessários para os assuntos da alçada do órgão central.

20. É preciso não esquecer que, conforme acentua o autor citado,

"o órgão central precisa elevar-se a uma posição de liderança em relação à administração de pessoal, em qualquer plano" (op. cit. pág. 39) 
e que, além disto, incumbe-lhe, como vimos, em relação às diretrizes, "coordená-las com a política geral da administração".

21. Como fazê-lo, sem conhecer o que se passa, isto é, sem exercer o contrôle sôbre a execução de leis, regulamentos e normas
de pessoal? É impossivel.

22. E o que dizer da coordenação, através do contrôle da execução, com a "política da administração"?

23. Para isto, é preciso que se entenda que, idealmente, o contrôle e a coordenação de tôdas as atividades de uma emprêsia deveriam estar nas mãos do seu dirigente máximo. Com o crescimento da organização, entretanto, é claro que isto se torna $1 \mathrm{~m}$ possivel e, então, parte-se para a descentralização e delegação.

24. Mas, delegar autoridade ou competência, não significa, em absoluto, deixar à sôlta ou livremente agir. Daí o principio de que, quanto maior o grau de descentralização, tanto mais necessária a existência de órgãos de contrôle e coordenação, para, de um lado - através do contrôle - permitir o acompanhamento sistemático da execução, para corrigir ("a priori" ou "a posteriori") ou propor a correção de erros, ou falhas, em relação às normas preestabelecidas, e, do outro, através da coordenação, para evitar que as atividades, assim descentralizadas, se dispersem, em relação ao planejamento global a elas referentes; para fazer com que elas sempre convirjam para o objetivo central programadu.

25. Nas grandes emprêsas - vimos - torna-se materialmente impossivel ao seu dirigente exercer, por si próprio, tão importantes tarefas. E o que faz êle? Transfere a outros órgãos
essas atribuições de controlar e coordenar.

26. Vejamos como funciona, na prática:

O dirigente de uma grande emprêsa resolve estabelecer cerias restrições na administração de pessoal. Vamos supor que elas
fôssem:

a) de caráter econômico-financeiro,

b) que se referissem, além disso, a exigências de determinados tipos - variáveis, conforme o caso - de seleção prévia: em alguns casos, a seleção só seria válida, através de prova; em outros, a simples entrevista soria suficiente, e, ainda, poderia ocorrer a hipótese de lis-
pensa de prova.

Isto para tôda a emprêsa; e

c) vamos supor, ainda, que a emprêsa contasse com sistemas de avaliação, de classificação de cargos e $1 \mathrm{~m}$ plano de remuneração, que, além de necessitarem de 
permanentes atualizações, precisariam de um contínuo contrôle na sua aplicação, uniformemente, por todos os órgãos da emprêsa que admitissem ou promovessem pessoal.

27. Pergunta-se: se tais politicas restritivas dissessem respeito a tôda a emprêsa, quais os órgãos que estariam em condições de, através do contrôle e coordenação, torná-las efetivas? Os descentralizados? Certamente que não.

28. Só o órgão central, que na hipótese sub "a", poderia até ser o financeiro, e, nas demais, o de pessoal, estariam, na realidade, na posição de estabelecerem meios concretos para a realização de tais politicas.

29. E a política sendo normal, também não há por que modificar o critério.

30. O que é preciso decidir, não é se deve ou não haver contrôle e coordenação, porque êles serão sempre necessários. A questão é saber quem os exercerá, se o dirigente, se, por delegação dêste, outro órgão e em que casos êle será exercido a priori ou a posteriori.

31. Na análise do trabalho, na fase da execução, o conhecimento completo, contínuo e sistemático de dois aspectos - quantitativo e qualitativo - é fator essencial ao exercício pleno do contrôle, ou acompanhamento, o que dá no mesmo.

32. É preciso que o órgão que edita e reedita normas acompanhe, pari passu, a respectiva aplicação pelos órgãos executivos, verificando, sistemàticamente, se essas normas estão sendo fielmente cumpridas, quanto ao fundo e à forma (até o aspecto da forma, por que os atos devam ser praticados - dentro do sentido da padronização - precisa ser conferido pelo órgão encarregado do contrôle).

33. Outro problema é o do Cadastro: no caso de existir um "sistema" de órgãos de Administração do Pessoal, o cadastro pode ser ou não centralizado. De preferência, é conveniente descentralizá-lo. Isto significa que cada órgão de pessoal executivo ficará incumbido do registro analitico dos assentamentos funcionais e demais dados, pormenorizados, de interêsse do serviço, no particular.

34. Mas - e aqui bate o ponto - o órgão central, normativo, coordenador e controlador das atividades de pessoal tem, também, necessidade de um cadastro que, entretanto, lida com outros elementos, de caráter geral e sintético, e que, não dizendo respeito às situações individuais de cada empregado ou funcionário (cadastro analítico dos órgãos executivos) necessita, contudo, de 
dados, permanentemente atualizados - principalmente os referentes aos cargos, quanto ao número (elementos quantitativos) e quanto à categoria (elementos qualitativos: denominaşão, avaliação, salário, classificação etc.) .

35. Assim, implicando, ou năo, em alterações qualitativas ou quantitativas, é preciso que o órgão central esteja sempre inteirado e atualizado sôbre a situação existente e que, inclusive, em tôdas as propostas sôbre as atividades básicas de administraçáo de pessoal (admissões, promoções, aumentos de quadro etc.) êle verifique - antes ou depois de aprovadas, preferentemente, antes - se elas obedecem, quanto ao fundo e à forma, às normas a re:ipeito prescritas. Como poderia o órgão central, de "Staff", normativo traçar as normas que lhe incumbem se não tivesse os clemento que só lhe adviriam do conhecimento pormenorizado do problema em execução?

36. Para pensar o contrário, teríamos então que modificar o esquema de organização, isto é, retrugredir à completa centralização ou à total descentralização, esta, na qual inexiste o orgão central normativo. Cada departamento faz o que entende, em têrmos de planejamento e execução, por seus próprios meios, s'm o sentido de unificação de normas, sem unidade programátıca, sem coordenação e contrôle. E, no caso, parece, não é o que se pretende.

37. É necessário, por fim, que se entenda: as atividades de coordenação e contrôle não envolvem necessàriamente - e c.riamente, no caso em exame, não envolvem - questões ligadas à hierarquia, à subordinação. Em absoluto: as atividades de coordenação e contrôle, pelos órgãos que planejam, ou que traçam as normas, ou que orientam. lhes são complementares e indispensáveis, não apenas para corrigirem possiveis falhas na execução, mas, pobretudo - na maioria das vêzes - para retificar as normas, o próprio planejamento que, na dinâmica administrativa, têm de ser. um melhor ajustamento continuamente revistos, visando sempre a

38. Por que todos hela exectção. "Č̃es dos órgãos da todos hoje não discutem o sentido das atribuiatravés das minudentes os acertos, na aplicaçâa informações obtidas, mostrar os erros e E porque todos já se habituar verbas, em relação aos orçamentos? de contas significa, inclusive, um isso e sentem que o con:rôle com dinheiros públicos ou de emprêteção prévia aos que lidam pelos órgãos de Fiscalização de Contas.

39. E o que é o tão famoso $P E R T$

Evaluation and Review Technos" PERT - literalmente "Programs de Programas) - - senãochnic" (Técnica de Avaliação e Revisão 
nicos, senão o conhecimento sistemático, continuo e minuciosíssimo, de todo o desenrolar de um programa, na sua fase executiva. Processa-se através do envio e reenvio aos órgãos de linha, do mesmo modo contínuo, sistemático e minudente, de instruções para manter ou alterar quadros do diagrama inicial, ou indicar as melhores alternativas, em têrmos de tempo e custo, visando a manter incólume o "caminho crítico" ("Critical Path").

40. Na verdade, o contrôle não implica, também necessàriamente, em tomada de decisões contra escalões superiores, salvo se por delegação.

41. Implica, isto sim, em tomada de conhecimento e, verificada qualquer dúvida na execução, ou no próprio planejamento, em indicar à alta administração, - quer dizer sugerir-lhe - as medidas julgadas convenientes. Mas, além disso, mesmo quando não ocorrer essa hipótese, implicará, sempre, em tomar conhecimento (cadastrando, quando fôr conveniente) de tôdas as alterações que se processarem na emprèsa.

42. Êste, bàsicamente, o verdadeiro sentido das atribuições geralmente cometidas a um órgão central, normativo, que, no caso em estudo, integra um "sistema" de órgãos de administração.

43. Nos problemas ligados à admissão de pessoal, é oportuno lembrar que, na maioria dos casos, embora todo o restante da parte executiva esteja a cargo dos órgãos seccionais ou periféricos - descentralizadas, portanto - as atividades de recrutamento e seleção - se bem que executivas, - vêm sendo exercitadas pelo úrgão central normativo. É o caso do DASP. Todos os concursos para o Serviço Público Federal, mesmo para as repartições da UInião nos Estados-Membros - são planejados e executados pelo $D A S P$, ainda que, em algums casos, êle delegue a competência da execução a órgãos federais sediados em unidades da Federação.

44. Esta, aliás, também, no particular, a opinião do citado "expert" em pessoal, Professor Henry Reining Jr., que parece até um pouco radical, quando opina:

"A realização de concursos para ingresso no servico, em caráter permanente, por exemplo, deve ser provàvelmente da exclusiva competência do órgão central de pessoal".

45. E explica porque:

"Na maioria dos casos em que ocorre o inverso, stige duplicidade de tarefas sem qualquer compensação, pois o órgão central de pessoal é capaz de obter, para basear seu trabalho, as mesmas informações que o órgão ministerial. Mesmo no caso de cargos privativos de um minis- 
tério, a manutenção de padrões, uniformes, é suficientemente importante para recomendar que todos os concursos sejam realizados pelo pessoal técnico do órgão central de pessoal" (op. cit. 41).

46. Isto demonstra, apenas, que a regra é a centralizaçāo, tanto das atividades normativas como de coordenação e contrôle, a bem, principalmente, da uniformidade das decisões dos órgãos de execução, descentralizados, e que essa cautela chega, por vêzes, $\therefore$ aconselhar que, no tocante ao processamento das admissões, o próprio órgão normativo se transforme, por exceção, em executivo.

47. O que tudo indica - e a idéia embora já antiga deve ser lembrada - é que descentralização é uma questão de medida, nunca tomada em sentido radical. Atende antes às peculiaridades de cada caso e - o que é importante - não se configura nem opera como compartimento estanque.

48. Para se atender à realidade, não se pode pensar am têrmos de descentralização total. Por outras palavras: sendo êsse embora o caminho certo, não quer isso significar que não exisłam situaçöes, atividades, órgãos ou funções que não possam ser centralizados. Ao contrário, hipóteses existem - como vimos - ụue indicam como melhor a centralização. E o que ocorre com as atividades normativas e igualmente sucede com as de coordenação e contrôle. E casos há - vimos no exemplo - em que fora do figurino descentralizado - que seria a regra geral - dela se excepcionam algumas funções ou atividades - que, a bem da uniformidade, ou por circunstâncias outras, têm de ser operadas não apenas planejadas - de modo centralizado.

49. E é exatamente aqui, no diagnóstico dessas nuanças, das hipóteses excepcionais que merecem tratamento especial diferente dos demais - que ressalta a figura do administrador. $\mathrm{Da}$ sua habilidade em estabeelcer o que deve e o que não deve ser descentralizado; dos meios de efetivo contrôle e de perfeita coordenação, e da gradação - da maior, da média, da minima e empreendimento. 